\title{
Anesthetic considerations for cesarean delivery in a parturient with hereditary hemorrhagic telangiectasia: a case report
}

\author{
Yuji Kamimura ${ }^{1 *} \mathbb{D}$, Toshiyuki Nakanishi', Aiji (Boku)Sato², Eisuke Kako ${ }^{1}$, Motoshi Tanaka $^{1}$ and Kazuya Sobue
}

\begin{abstract}
Background: Hereditary hemorrhagic telangiectasia $(H H T)$, also known as Rendu-Osler-Weber syndrome, is a rare autosomal dominant disorder characterized by mucocutaneous telangiectasia and arteriovenous malformations (AVMs). There are some anesthetic considerations for cesarean delivery in a parturient with HHT.

Case presentation: A 27-year-old parturient with pulmonary hemorrhage was admitted to our tertiary perinatal center. She was first diagnosed with HHT and a cesarean delivery using spinal anesthesia at 37 weeks of gestation was initially planned. However, magnetic resonance imaging (MRI) at 32 weeks of gestation revealed spinal AVM ranging from the thoracic to the lumbar levels. Thus, elective cesarean delivery under general anesthesia was planned. The parturient had an uneventful perioperative course.

Conclusions: HHT should be considered as a differential diagnosis when parturients develop pulmonary hemorrhage. In a cesarean delivery of parturients with HHT, spinal MRI during pregnancy can help in deciding the anesthetic procedure to be used.
\end{abstract}

Keywords: Hereditary hemorrhagic telangiectasia, Rendu-Osler-Weber syndrome, Pulmonary arteriovenous malformation, Cesarean delivery, Spinal magnetic resonance imaging

\section{Background}

Hereditary hemorrhagic telangiectasia (HHT), also known as Rendu-Osler-Weber syndrome, is a rare autosomal dominant disorder characterized by mucocutaneous telangiectasia and arteriovenous malformations (AVMs). The prevalence of $\mathrm{HHT}$ is estimated to be 1 in about 2000-40,000 [1]. In patients with HHT, pulmonary and cerebral AVMs were at least $30 \%$ and $10-20 \%$, respectively [2], while spinal AVMs were $1-8 \%[3,4]$.

Parturients with HHT can have a significant disease progression $[2,5]$, which can cause major complications [5-7]. In the report examining 262 pregnancies and 111 women with HHT, major pulmonary AVM bleeding,

\footnotetext{
* Correspondence: ez4pixy1118@gmail.com

'Department of Anesthesiology and Intensive Care Medicine, Nagoya City University Graduate School of Medical Sciences, 1 Kawasumi, Mizuho-cho, Mizuho-ku, Nagoya 467-8601, Japan

Full list of author information is available at the end of the article
}

stroke, and maternal death were found in $1 \%, 1.2 \%$, and $1 \%$ [5], respectively. Thus, parturients with HHT are at high risk and should thoroughly consider their anesthetic plan. We herein report the anesthetic management for cesarean delivery in a parturient with HHT with a ruptured pulmonary AVM and undiagnosed spinal AVMs.

\section{Case presentation}

A 27 -year-old, 52-kg, 156-cm woman (G4, P1), with a previous uneventful term vaginal delivery, had epistaxis a few times a month before pregnancy. At 30 weeks of gestation, she was admitted to a local hospital's emergency department due to excruciating back pain and dyspnea. Computed tomography revealed a ruptured pulmonary AVM $(36 \times 21 \mathrm{~mm})$ in the left lower lobe. She was transferred to our tertiary perinatal center after embolization (Fig. 1) and was first diagnosed with HHT because of recurrent epistaxis, pulmonary AVM, and

\section{Springer Open}

(อ) The Author(s). 2021 Open Access This article is licensed under a Creative Commons Attribution 4.0 International License, which permits use, sharing, adaptation, distribution and reproduction in any medium or format, as long as you give appropriate credit to the original author(s) and the source, provide a link to the Creative Commons licence, and indicate if changes were made. The images or other third party material in this article are included in the article's Creative Commons licence, unless indicated otherwise in a credit line to the material. If material is not included in the article's Creative Commons licence and your intended use is not permitted by statutory regulation or exceeds the permitted use, you will need to obtain permission directly from the copyright holder. To view a copy of this licence, visit http://creativecommons.org/licenses/by/4.0/. 


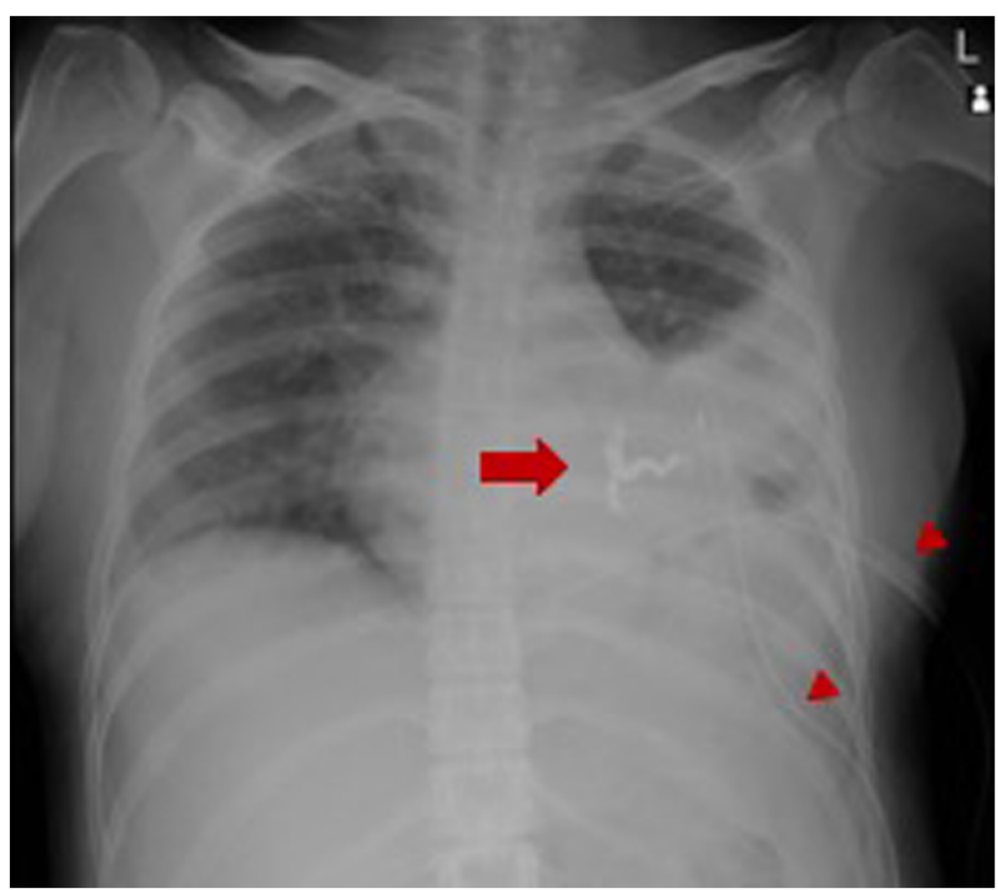

Fig. 1 Chest X-ray imaging at 30 weeks of gestation. Embolization coils (the arrow) and chest tubes (arrowheads) are placed for the pleural hemothorax treatment due to the ruptured arteriovenous malformation

positive family history. Several discussions were held by a multidisciplinary team comprising obstetric anesthesiologists, obstetricians, pediatricians, respiratory physicians, and interventional radiologists to seek the most appropriate management. Our obstetricians preferred to avoid vaginal delivery owing to the risk of rerupture of pulmonary AVM and rupture of undiagnosed pelvic or other areas' AVMs during vaginal delivery. Our interventional radiologists also agreed that the possibility of pulmonary AVM rerupture during vaginal delivery was not $0 \%$, even after embolization. Therefore, elective cesarean delivery by neuraxial anesthesia at 37 weeks of gestation was planned. Preoperative examinations revealed no abnormal physical or laboratory findings. Magnetic resonance imaging (MRI) at 32 weeks of gestation revealed spinal AVM ranging from the thoracic to the lumbar levels (Figs. 2 and 3), but AVM was not present in the brain. To avoid puncturing the spinal AVM with neuraxial techniques, the anesthetic plan was changed from neuraxial anesthesia to general anesthesia. A hybrid operating where arterial embolization could be performed in case of pulmonary AVM rerupture was opted for performing the surgery.

After arriving in the operating room, general anesthesia was induced using $300 \mu \mathrm{g}$ fentanyl, $100 \mathrm{mg}$ propofol, and $60 \mathrm{mg}$ rocuronium in the $30^{\circ}$ left lateral tilt position with standard monitoring and direct left radial arterial pressure. The trachea was easily intubated by applying cricoid pressure. Mechanical ventilation settings were peak inspiratory pressure of 15 $\mathrm{cmH} 2 \mathrm{O}$, positive end-expiratory pressure of $5 \mathrm{cmH} 2 \mathrm{O}$, frequency of 15 breaths per minute, and inspired oxygen fraction of $40 \%$. The target range for end-tidal $\mathrm{CO} 2$ was set at $30-35 \mathrm{mmHg}$. Anesthesia was maintained with oxygen, air, target-controlled infusion of $2.6 \mu \mathrm{g} / \mathrm{ml}$ propofol, and $0.2 \mu \mathrm{g} / \mathrm{kg} / \mathrm{min}$ remifentanil. She remained hemodynamically stable throughout the surgery, with $\mathrm{SpO} 2$ over $99 \%$. Five minutes after the induction, a 2496-g newborn was delivered with Apgar scores of 7 and 9 at $1 \mathrm{~min}$ and $5 \mathrm{~min}$, respectively. The umbilical arterial blood gas had $\mathrm{pH} 7.28$ and base excess $-4.0 \mathrm{mEq} / \mathrm{l}$. After the surgery, intravenous 1000 $\mathrm{mg}$ acetaminophen and $100 \mathrm{mg}$ sugammadex were administered, and her trachea was extubated soon after confirming spontaneous breathing to avoid coughing and hypertension. The total surgical and anesthesia durations were $32 \mathrm{~min}$ and $54 \mathrm{~min}$, respectively, with blood loss of $904 \mathrm{ml}$, including the amniotic fluid. She had an uneventful postpartum period and was discharged with her baby on the fifth postoperative day.

\section{Discussion}

We experienced a HHT case with a ruptured pulmonary AVM and undiagnosed spinal AVMs. Since spinal MRI 


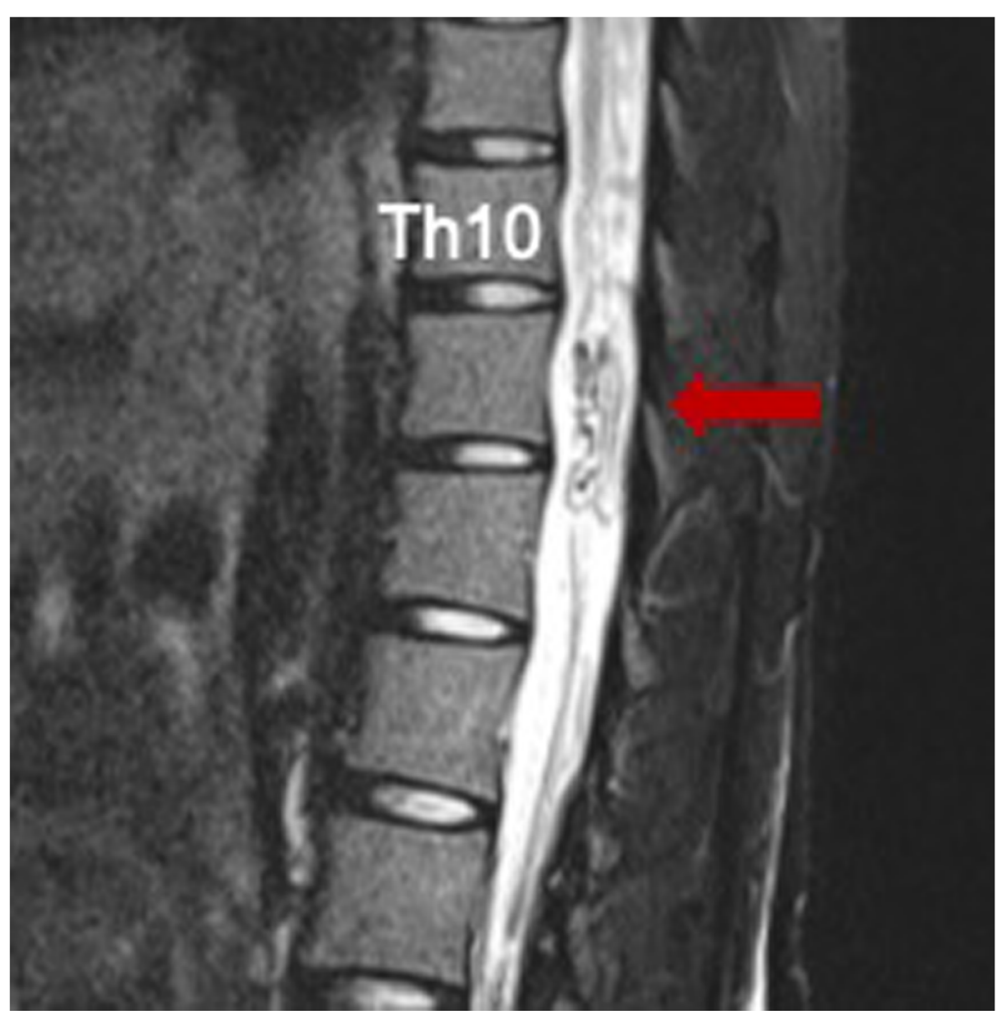

Fig. 2 Magnetic resonance imaging (T2-weighted image) in the thoracic level at 32 weeks of gestation. Flow void (the arrow) suggests a dilated draining vein. Th10, tenth thoracic vertebra

during pregnancy revealed AVMs ranging from the thoracic to the lumbar levels, we selected general anesthesia. This case provides two important clinical suggestions.

First, HHT should be considered as a differential diagnosis when parturients develop pulmonary hemorrhage. Although HHT is rarely diagnosed before pregnancy [5], pulmonary AVM exists in 30\% patients with HHT [2], of which 1\% experience significant pulmonary AVM bleeding [5]. Notably, the intrapulmonary shunt fraction increases during pregnancy [8], possibly due to increased pulmonary blood flow caused by increased blood volume and cardiac output and decreased venous distensibility due to increased progesterone levels $[9,10]$.

Second, spinal MRI during pregnancy can be useful in deciding the anesthesia technique in parturients with HHT. Neuraxial anesthesia was performed in 92 of $185(50 \%)$ deliveries in women with HHT without prior screening for spinal AVMs, none of which were complicated by an epidural bleed or other serious complications [7]. On the contrary, several published cases have reported that parturients with spinal AVMs developed spinal subdural hematoma after neuraxial anesthesia [11, 12]. Changes in cord hemodynamics by spinal AVMs can cause widespread enlargement of the epidural veins, increasing the chance of trauma. Furthermore, cerebrospinal fluid loss can result in tension on the wall of spinal AVMs [13]. We believe that neuraxial anesthesia can only be administered safely in the absence of lumbar level lesions after spinal MRI.

Choosing an anesthesia technique involves balancing the risks of general and neuraxial anesthesia. The risk of general anesthesia included AVM rupture while performing anesthesia, especially that caused by a pressor response to laryngoscopy and positive pressure to mechanical ventilation. The risk of neuraxial anesthesia included puncture of spinal AVMs with neuraxial techniques. Moreover, vasodilatation produced by neuraxial anesthesia can also increase the shunt across AVMs [14]. A previous review also mentioned that spinal AVMs were contraindications to neuraxial anesthesia [6]. In our parturient, general anesthesia was performed based on the MRI findings at 32 weeks of gestation. During general anesthesia, tracheal intubation was carefully performed along with radial arterial pressure monitoring and ventilation with a small tidal volume to avoid high peak inspiratory pressure and reduce the risk of rupturing pulmonary AVMs [14]. 


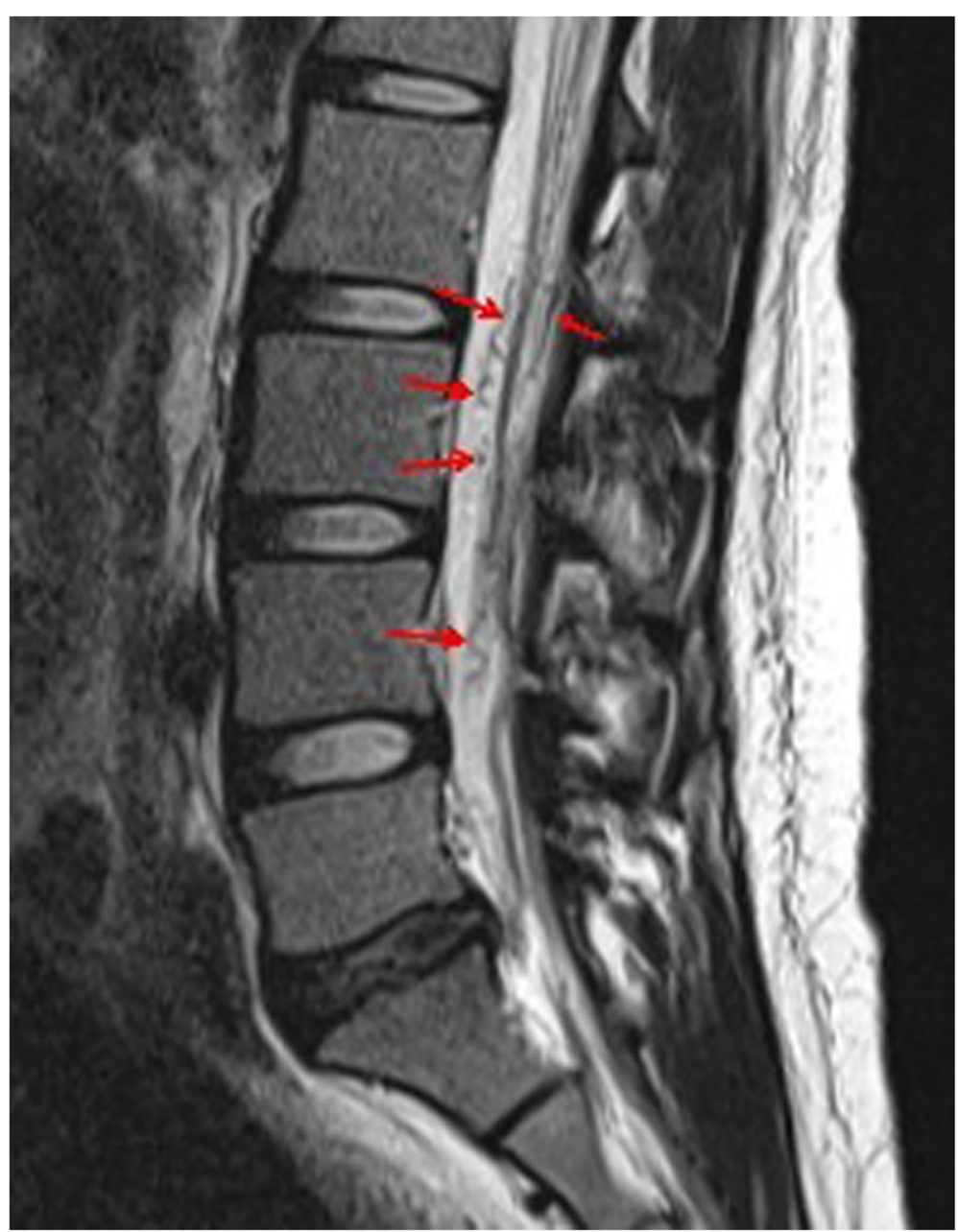

Fig. 3 Magnetic resonance imaging (T2-weighted image) in the lumbar level at 32 weeks of gestation. Flow voids (the arrows) suggest dilated draining veins

In conclusion, we report on a case of HHT with a ruptured pulmonary AVM and undiagnosed spinal AVMs. HHT should be considered as a differential diagnosis when parturients developed pulmonary hemorrhage. In a cesarean delivery of parturients with HHT, spinal MRI during pregnancy can help in deciding the anesthetic procedure.

\section{Abbreviations}

AVM: Arteriovenous malformation; HHT: Hereditary hemorrhagic

telangiectasia; MRI: Magnetic resonance imaging; $\mathrm{SpO}_{2}$ : Peripheral oxygen saturation

\section{Acknowledgements}

Not applicable.

\section{Authors' contributions}

YK wrote the manuscript and performed anesthetic management. AS helped in revising the manuscript and considering the anesthetic plan. EK and MT helped in writing the manuscript and performing the anesthetic management. TN and KS helped in writing and revising the manuscript. All authors read and approved the final manuscript.

\section{Funding}

This case report was supported only by the institutional sources.

\section{Availability of data and materials}

Not applicable.

Ethics approval and consent to participate

Not applicable. In our institution, the publication of case reports is exempted from ethics committee approval.

\section{Consent for publication}

Written informed consent was obtained from the parturient for publication of this case report and accompanying images.

\section{Competing interests}

The authors declare no competing interests.

\section{Author details}

'Department of Anesthesiology and Intensive Care Medicine, Nagoya City University Graduate School of Medical Sciences, 1 Kawasumi, Mizuho-cho, Mizuho-ku, Nagoya 467-8601, Japan. ${ }^{2}$ Department of Anesthesiology, Aichi Gakuin University School of Dentistry, 2-11 Suemori-dori, Chikusa-ku, Nagoya 464-8651, Japan. 
Received: 8 January 2021 Revised: 7 February 2021

Accepted: 14 February 2021 Published online: 01 March 2021

References

1. Guttmacher AE, Marchuk DA, White RI Jr. Hereditary hemorrhagic telangiectasia. N Engl J Med. 1995;333:918-24.

2. Begbie ME, Wallace GM, Shovlin CL. Hereditary haemorrhagic telangiectasia (Osler-Weber-Rendu syndrome): a view from the 21st century. Postgrad Med J. 2003;79:18-24.

3. Roman G, Fisher M, Perl DP, Poser CM. Neurological manifestations of hereditary hemorrhagic telangiectasia (Rendu-Osler-Weber disease): report of 2 cases and review of the literature. Ann Neurol. 1978;4:130-44.

4. Bayrak-Toydemir P, Mao R, Lewin S, McDonald J. Hereditary hemorrhagic telangiectasia: an overview of diagnosis and management in the molecular era for clinicians. Genet Med. 2004:6:175-91.

5. Shovlin CL, Sodhi V, McCarthy A, Lasjaunias P, Jackson JE, Sheppard MN. Estimates of maternal risks of pregnancy for women with hereditary haemorrhagic telangiectasia (Osler-Weber-Rendu syndrome): suggested approach for obstetric services. BJOG. 2008;115:1108-15.

6. Lomax $\mathrm{S}$, Edgcombe $\mathrm{H}$. Anesthetic implications for the parturient with hereditary hemorrhagic telangiectasia. Can J Anaesth. 2009;56:374-84.

7. de Gussem EM, Lausman AY, Beder AJ, Edwards CP, Blanker MH, Terbrugge $K G$, et al. Outcomes of pregnancy in women with hereditary hemorrhagic telangiectasia. Obstet Gynecol. 2014;123:514-20.

8. Swinburne AJ, Fedullo AJ, Gangemi R, Mijangos JA. Hereditary telangiectasia and multiple pulmonary arteriovenous fistulas. Clinical deterioration during pregnancy. Chest. 1986;89:459-60.

9. Gershon AS, Faughnan ME, Chon KS, Pugash RA, Clark JA, Bohan MJ, et al. Transcatheter embolotherapy of maternal pulmonary arteriovenous malformations during pregnancy. Chest. 2001;119:470-7.

10. Shovlin CL, Winstock AR, Peters AM, Jackson JE, Hughes JM. Medical complications of pregnancy in hereditary haemorrhagic telangiectasia. QJM. 1995:88:879-87.

11. Hirsch NP, Child CS, Wijetilleka SA. Paraplegia caused by spinal angioma - possible association with epidural analgesia. Anesth Analg. 1985; 64:937-40.

12. Abut $Y$, Erkalp K, Bay B. Spinal subdural hematoma: a pre-eclamptic patient with a spinal arteriovenous malformation. Anesth Analg. 2006;103:1610.

13. Eldridge AJ, Kipling M, Smith JW. Anaesthetic management of a woman who became paraplegic at 22 weeks' gestation after a spontaneous spinal cord haemorrhage secondary to a presumed arteriovenous malformation. Br J Anaesth. 1998:81:976-8.

14. Crawford M, Burns R, Cooper S, Mackay T. Hereditary haemorrhagic telangiectasia in pregnancy: regional and general anaesthesia. Int J Obstet Anesth. 2018;33:84-6.

\section{Publisher's Note}

Springer Nature remains neutral with regard to jurisdictional claims in published maps and institutional affiliations.

\section{Submit your manuscript to a SpringerOpen ${ }^{\circ}$ journal and benefit from:}

- Convenient online submission

- Rigorous peer review

- Open access: articles freely available online

- High visibility within the field

- Retaining the copyright to your article

Submit your next manuscript at $\boldsymbol{\nabla}$ springeropen.com 